\title{
LA DIFUSIÓN DE LAS POLÍTICAS DE CANNABIS MEDICINAL EN AMÉRICA LATINA (2015-2017)*
}

\author{
Virginia Labiano**
}

\section{RESUMEN}

Entre 2015 y 2017, ocho países de América Latina y el Caribe legislaron sobre cannabis medicinal: la Argentina, Chile, Perú, Paraguay, Colombia, México, Jamaica y Puerto Rico. Este proceso regulatorio se produce dos décadas más tarde que la ley pionera en la materia, la dispuesta en 1992 por Israel. Asimismo, se observan varias similitudes en el contenido de estas leyes. En el presente trabajo se plantea que las políticas de cannabis medicinal se muestran como un caso de difusión en el cual operan dos mecanismos reconocidos por la literatura: imitación normativa y competencia. El propósito del artículo es realizar una primera aproximación a este objeto, a fin de aportar a la literatura sobre adopción de políticas de cannabis medicinal, la cual es escasa a nivel mundial y casi inexistente para América Latina. Después de describir el contexto regional en el que ocurrieron las leyes, se presenta el marco teórico de la difusión internacional de políticas y la metodología de la cual se valió la investigación. Luego se desarrolla el análisis de los casos para examinar la presencia o ausencia de los mecanismos de difusión. En el último apartado se realiza una reflexión en torno a las políticas de cannabis medicinal en América Latina.

PALABRAS CLAVE: DIFUSIÓN - CANNABIS MEDICINAL - AMÉRICA LATINA

* Una primera versión de este artículo fue presentada en el Congreso "Cinco Años de Regulación del Cannabis”, organizado por la Facultad de Ciencias Sociales (Universidad de la República) y Monitor Cannabis Uruguay. Realizado en Montevideo, del 10 al 12 de diciembre de 2018.

** Candidata a doctora en Ciencia Política por la Universidad Nacional de San Martín; se desempeña como becaria doctoral Conicet. Correo electrónico: <vlabiano@unsam.edu.ar>. 


\section{INTRODUCCIÓN}

Entre 2015 y 2017, ocho países de América Latina y el Caribe legislaron sobre cannabis medicinal: la Argentina, Chile, Perú, Paraguay, Colombia, México, Jamaica y Puerto Rico. Como dijimos, este proceso regulatorio se produjo dos décadas más tarde que la ley pionera en la materia, la establecida en 1992 por Israel. Podemos observar ciertas similitudes (véase cuadro comparativo en Anexo), por las que tal tendencia regulatoria podría analizarse a la luz de lo que en ciencia política se identifica como "difusión internacional de políticas".

Se entiende por difusión al proceso mediante el cual la adopción y formulación de una política se propaga entre diferentes países. En el presente trabajo se plantea que las políticas de cannabis medicinal se muestran como un caso de difusión internacional en el cual operan dos mecanismos reconocidos por la literatura: imitación normativa y competencia. El propósito central del trabajo es realizar una primera aproximación a este objeto, a fin de aportar a la literatura sobre adopción de políticas de cannabis medicinal, la cual es escasa a nivel mundial y casi inexistente para América Latina. ${ }^{[1]}$ El artículo se organiza en cuatro apartados más. Primero, se describe la genealogía del Régimen Internacional de Fiscalización de Sustancias y el tratamiento que le da al cannabis. A continuación se presenta el marco teórico de la difusión internacional de políticas y la metodología de la cual se valió la investigación. Luego se desarrolla el análisis de los casos para examinar la presencia o ausencia de los mecanismos de difusión identificados por la literatura. En el último apartado se realiza una reflexión en torno a las políticas de cannabis medicinal en América Latina.

\section{EL RÉGIMEN INTERNACIONAL DE FISCALIZACIÓN DE SUSTANCIAS}

Lo que comúnmente se denomina como drogas ilícitas no siempre ha gozado de ese estatus jurídico, más bien esta situación responde al desarrollo de un Régimen Internacional de Fiscalización de Sustancias (RIFs), es decir, a la entrada en vigencia de un conjunto de tratados internacionales firmados entre 1912 y 1988, que cambió la legitimidad de los usos de los psicoactivos. ${ }^{[2]}$

[1] Constituye una excepción el trabajo de Carrillo (2013).

[2] Se pueden consultar este conjunto de tratados agrupados en el capítulo VI: "Estupefacientes y sustancias psicotrópicas, de los instrumentos depositados ante el secretario general de la Naciones Unidas". Véase Naciones Unidas (s/f). 
Partimos de la definición de régimen internacional que aporta Constanza Sánchez Avilés:

[...] un régimen existe cuando los estados y otros actores internacionales relevantes, con el objetivo de evitar los costes de la acción individual y no coordinada, se ponen de acuerdo en limitar su soberanía mediante una serie de normas y procedimientos a las que ajustan su comportamiento en un ámbito concreto (Sánchez Áviles, 2014: 126).

En nuestro estudio la cooperación entre países se da en cuanto a restringir actividades económicas en relación con un conjunto de sustancias, cuando estas no sean destinadas para uso médico o científico.

En la confluencia de factores que llevaron a la emergencia de un régimen internacional de control de sustancias hay tres que tienen un gran peso: a) el desarrollo entre mediados y fines del siglo XIX de la industria química y farmacéutica, con progresos como el aislamiento de la morfina y la heroína del opio; b) el aislamiento de la cocaína de la planta de coca y c) la perfección de los métodos de inyección hipodérmica (Nadelmann, 1990), lo cual pronto convirtió al sector farmacéutico en uno de los más importantes de la economía de algunas naciones europeas. Sin embargo, y en paralelo, aumentó también la disponibilidad de estas sustancias para su consumo "no médico". La extensión de este uso provocó la reacción de grupos promotores de la templanza, que se articularon internacionalmente, y de misioneros religiosos de Estados Unidos y Gran Bretaña en Asia -China, Filipinas-. De modo que en el origen de este régimen global de prohibición -como lo denomina Ethan Nadelmann (1990)encontramos la confluencia de intereses materiales y consideraciones morales.

Si bien el RIFs se inicia formalmente en 1912 con la firma de la Convención Internacional del Opio y los subsiguientes tratados, cambia su naturaleza en 1961 cuando se firma la Convención Única. Transforma su función de regular el comercio internacional de estupefacientes e impedir el desvío de drogas de los canales de comercio lícito, a prohibir todos los usos no "médicos y científicos" y convertir las actividades vinculadas con la producción y circulación de un conjunto de sustancias en delitos internacionales sujetos a sanciones (Bewley-Taylor y Jelsma, 2011; Carstairs, 2005; Room, 2015; Sánchez Avilés, 2014; Sinha, 2001).

Esta transformación iniciada con la Convención Única de 1961 sobre Estupefacientes tuvo tres objetivos: anular y sustituir todos los tratados previos; reducir el número de órganos internacionales dedicados al control; y 
ampliar la fiscalización a otras plantas que sirven de materia prima para la elaboración de estupefacientes. ${ }^{[3]}$

Es así como se amplió el control a un centenar de sustancias, mayormente de carácter orgánico, como la paja de adormidera, la hoja de coca y la planta de cannabis - a excepción de sus hojas y semillas- que fueron clasificadas en un sistema de cuatro listas, siguiendo el criterio establecido en 1931 de ordenarlas en torno a su capacidad de generar dependencia y sus probables usos médicos. ${ }^{[4]}$ En ellas se incluyó el cannabis en las listas i y iv, lo que supuso considerar que tiene propiedades muy adictivas y nulo valor terapéutico, y nivel de peligrosidad comparable al de la heroína. Adicionalmente, sometió al mismo tipo de control a alcaloides extraídos y concentrados de las plantas, es decir, equiparó la hoja de coca con la cocaína (Bewley-Taylor y Jelsma, 2011).

La radicalidad del principio de "que se limite el uso de estupefacientes a los fines médicos y científicos y se establezca una cooperación y una fiscalización internacionales constantes para el logro de tales finalidades y objetivos" (Naciones Unidas, 1961: 13) implicó la supresión de los usos tradicionales o religiosos que se daba a estas plantas en muchos países de América, Asia y África. ${ }^{[5]}$

Esta Convención es una bisagra en el desarrollo del RIFs porque por primera vez introduce disposiciones penales en un tratado internacional de control de estupefacientes ampliamente aceptado. Es decir, marca un antes y un después del RIFs porque, como expresa Robin Room: "lo que había sido un sistema que se ocupaba principalmente de controlar el movimiento internacional de drogas se convirtió en un sistema comprometido con la

[3] Hasta ese momento el régimen se concentraba en tres plantas: la adormidera -por el opio-, el arbusto de coca y -en términos más bien comerciales- el cannabis.

[4] Nos referimos a los criterios de clasificación que se establecieron en la Convención para Limitar la Manufactura y Regular la Distribución de Estupefacientes de 1931 (Liga de las Naciones, 1931).

[5] El historiador William B. McAllister ha analizado las conformación de grupos de naciones y cómo la puja por defender sus intereses se cristalizó en las convenciones de 1961 y 1971 -particularmente entre países cultivadores de orgánicos versus países productores de sintéticos-, revelando que "el régimen actual de fiscalización de drogas demuestra que el sistema internacional ha funcionado durante mucho tiempo en beneficio de las naciones poderosas" y que las "las diferencias culturales desempeñan un papel importante en los conflictos internacionales" (McAllister, 1991: 162). No solo sus intereses económicos defendieron estos países sino también el ejercicio de la medicina occidental y los usos socialmente aceptados en sus territorios de sustancias psicoactivas como el café, el tabaco y el alcohol. 
tutela de prohibiciones sobre el uso no médico de las drogas, con las leyes penales de cada país como medio de aplicación” (Room, 2015: 1379).

Una década después, se firmó la Convención sobre Sustancias Sicotrópicas de 1971 (Naciones Unidas, 1971),que en vez de fiscalizar materias primas, regulaba moléculas, y que surgió como respuesta al importante aumento del uso de sustancias sintéticas en Estados Unidos y Europa Occidental. ${ }^{[6]}$ Nuevamente se establecieron cuatro listas, basándose en el criterio del potencial valor terapéutico de una sustancia y en los posibles riesgos derivados de su consumo, solo que el orden es inverso (véanse cuadro 1 y cuadro 2). Allende los problemas conceptuales de la clasificación, ${ }^{[7]}$ la Convención de 1971 puso bajo control sustancias como las anfetaminas, las benzodiacepinas, los barbitúricos y sustancias psicodélicas; además, como bien indica Sánchez Avilés,

[...] se someten a fiscalización los principios activos contenidos en sustancias vegetales con efectos psicoactivos, tales como la mescalina, principal alcaloide del peyote, el tetrahidrocannabinol (THC), componente básico del cannabis, la psilocibina presente en los hongos alucinógenos o la catinona (DMT), componente psicoactivo de la ayahuasca (Sánchez Avilés, 2014: 162).

La ampliación de la fiscalización a estas sustancias no hizo desaparecer su demanda para fines recreativos sino que dio lugar al crecimiento del tráfico internacional de drogas, operado por un conjunto global de actores dispuestos a evadir las leyes y los controles estatales para dominar este lucrativo mercado; a su vez, en la condición de ilegalidad del mercado surgió la violencia para mediar las relaciones sociales. Como resultado, el problema

[6] El 17 de junio de ese mismo año, Richard Nixon -presidente de los Estados Unidos, principal país consumidor de psicoactivos- definió el abuso de drogas como el "enemigo público número uno" contra el que había que emprender "una ofensiva total a nivel mundial que abordara los problemas de la oferta" (Nixon, 1971). Los medios de comunicación denominaron esta declaración como "Guerra contra las drogas" [War on drugs], pese a que en el discurso no se acuña la frase como tal.

[7] Sallam, Bewley-Taylor y Jelsma señalan que la Convención de 1961 buscó regular las drogas "estupefacientes" y "según el léxico médico, este término alude a aquellas sustancias que provocan somnolencia o sueńo; no obstante, la cocaína (un estimulante) y el cannabis (un alucinógeno) están clasificados al amparo de esta convención" (Hallam, Bewley-Taylor y Jelsma, 2014: 7). A su vez, ocurre algo similar con la Convención de 1971, entre las drogas "psicotrópicas" reguladas se encuentran la buprenorfina - un estupefaciente-, la anfetamina -un estimulante- y el LSD -un enteógeno. 


\section{Cuadro 1. Convención Única sobre Estupefacientes de 1961}

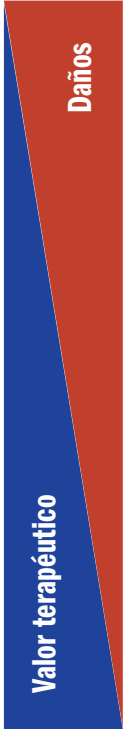

Lista IV

Ciertos estupefacientes, también clasificados en la Lista I con "propiedades particularmente peligrosas" y escaso o nulo valor terapéutico (por ej. cannabis y su resina, heroína).

Sustancias que son muy adictivas y de probable uso indebido, y

Lista I precursores que se pueden convertir en estupefacientes (por ej. extractos y tintura de cannabis, opio, heroína, metadona, cocaína, hoja de coca, oxicodona).

Lista II

Sustancias que son menos adictivas y cuyo uso indebido es menos probable que las de la Lista I (por ej. dodeína, dextropropoxifeno).

Preparados farmacéuticos que contienen una cantidad baja de estupefacientes, son muy poco susceptibles de uso indebido y están Lista III exonerados de la mayoría de las medidas de fiscalización impuestas sobre las sustancias que contienen (por ej. menos de 2,5\% de codeína, menos de $0,1 \%$ de cocaína).

Fuente: Hallam, Bewley-Taylor y Jelsma (2014).

\section{Cuadro 2. Convenio sobre Sustancias Sicotrópicas de 1971}

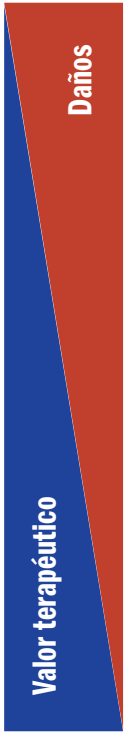

Psicotrópicos que presentan un alto riesgo de uso indebido y que

Lista I constituyen una amenaza especialmente grave para la salud pública, con escaso o nulo valor terapéutico (por ej. isómeros de THC, LSD, MDMA).

Psicotrópicos que presentan un riesgo de uso indebido y que

Lista II constituyen una amenaza grave para la salud pública, con un valor terapéutico de bajo a moderado (por ej. $\Delta 9$ tetrahidrocannabinol, dronabinol, anfetaminas).

Psicotrópicos que presentan un riesgo de uso indebido y que

Lista III constituyen una amenaza grave para la salud pública, con un valor terapéutico de moderado a alto (por ej. barbitúricos, buprenorfina).

Psicotrópicos que presentan un riesgo de uso indebido y que

Lista IV constituyen una amenaza menor para la salud pública, con un alto valor terapéutico (por ej. tranquilizantes, incluido el diazepam).

Fuente: Hallam, Bewley-Taylor y Jelsma (2014). 
de las drogas comenzó a vincularse con la seguridad de los estados y el narcotráfico.

En este nuevo escenario, entre el 25 de noviembre y el 20 de diciembre de 1988 se reunieron en Viena 106 países para abordar la ampliación del régimen de fiscalización. Como resultado se configuró la Convención de las Naciones Unidas contra el Tráfico Ilícito de Estupefacientes y Sustancias Sicotrópicas. A través del artículo 3 se instó a las partes a adoptar las medidas necesarias para tipificar como delitos penales en su derecho interno absolutamente todas las actividades que puedan vincularse al tráfico de drogas. De igual forma, se expandió la fiscalización hacia los precursores capaces de producir drogas, los cuales fijó en dos tablas (cuadro 3).

Como podemos apreciar, con la Convención de las Naciones Unidas contra el Tráfico Ilícito de Estupefacientes y Sustancias Sicotrópicas se hizo evidente el cambio en el objetivo del RIFs. Inicialmente, los tratados tenían como fin controlar el comercio internacional de sustancias psicoactivas para uso médico y garantizar suministros adecuados para tal fin, particularmente de opiáceos. Sin embargo, con el paso del tiempo, la atención comenzó a centrarse más "en la lucha contra los mercados ilícitos que habían surgido como subproducto del sistema de prohibición, incluyendo por primera vez la fiscalización de los precursores utilizados en la preparación de drogas sometidas a control" (Room, 2015: 1379).

Todo este entramado regulatorio tuvo consecuencias sobre el cannabis, que en el siguiente subapartado abordamos de manera específica.

\section{Cuadro 3. Convención sobre el Tráfico Ilícito de Estupefacientes y Sustancias Sicotrópicas de 1988}

\begin{tabular}{c} 
Tabla I $\begin{array}{l}\text { Precursores de sustancias sicotrópicas como efedrina, piperonal, safrol, ácido } \\
\text { fenilacético, ácido lisérgico y algunos reactivos clave usados para la conversión de } \\
\text { morfina en heroína así como el permanganato potásico usado en la extracción de } \\
\text { cocaína. }\end{array}$ \\
\hline Tabla II \\
$\begin{array}{l}\text { Una amplia gama de reactivos y disolventes que se pueden usar en la producción } \\
\text { ilícita de estupefacientes y sustancias sicotrópicas, pero también tienen usos } \\
\text { industriales lícitos (como acetona, éter etílico, tolueno y ácido sulfúrico). }\end{array}$
\end{tabular}

Fuente: Hallam, Bewler-Taylor y Jelsma (2014). 


\section{EL RÉGIMEN INTERNACIONAL DE FISCALIZACIÓN DE SUSTANCIAS Y EL CANNABIS}

Se estima que el cannabis ya era utilizado en el año 4000 a.C. en Asia central y el noroeste de China, y existen documentos escritos que datan del año 2700 a.C. en la farmacopea del emperador Chen-Nong y desde allí su expansión al resto del mundo: a la India -alrededor del año 1500 a.C.-; al Cercano Oriente y Oriente Medio -aproximadamente en el 900 a.C.-; a Europa -cerca del año 800 a.C.-; a distintos lugares de Asia sudoriental -siglo II-; África -siglo XI- y al continente americano junto con la colonización (Pietschmann, 2007). ${ }^{[8]}$ Su consumo no solo se restringía a las experiencias psicotrópicas -capacidad estimulante, depresora y alucinógena-, sino que también sus fibras eran utilizadas para la elaboración de textiles, cuerdas, redes, entre otros, y sus semillas se procesaban para la fabricación de aceite y otros comestibles.

Sin embargo, en el siglo xIX comenzaron a darse las primeras prohibiciones a nivel nacional en países como Egipto, Turquía, Grecia, Sudáfrica y Brasil, a menudo como "un mecanismo de control social de la fuerza de trabajo y de grupos que operaban al margen de la sociedad convencional" (Bewley-Taylor, Blickman y Jelsma 2014: 9), ${ }^{[9]}$ y también en respuesta a las presiones de los grupos por la templanza que a fines de esa centuria expandieron su lucha contra el alcohol a otras sustancias psicoactivas. Consintiendo a tales grupos, la Cámara de los Comunes del Reino Unido junto con el gobierno colonial de la India establecieron dos comisiones: la Comisión Real sobre el opio, para investigar si el comercio de tal sustancia podía ser abolido y el impacto económico de hacerlo, y por su parte, la Comisión sobre Estupefacientes de Cáñamo de la India para investigar la "cuestión de la ganja” (Indian Hemp Drugs Commission) (Mead, 2014). ${ }^{[10]}$ El resultado de esta segunda comisión fue un informe de 3.698 páginas compiladas

[8] Para una cronología más exacta y extensa, véase Russo (2014).

[9] Por ejemplo, durante la invasión de Napoleón Bonaparte a Egipto, el 8 de octubre de 1800 se publicó una ordenanza en El Cairo que cita Antonio Escohotado: "Artículo único. Queda prohibido en todo Egipto hacer uso del brebaje fabricado por ciertos musulmanes con el cáñamo (haschisch), así como fumar las semillas de cáñamo. Los bebedores y fumadores habituales de esta planta pierden la razón y son presa de delirios violentos que les llevan a excesos de toda especie" (Escohotado, 1998: 349). Como indica el autor, la medida denota "no tener remota idea botánica, farmacológica y cultural de lo que condena" (Escohotado, 1998: 350) ya que ni el hachís es líquido ni las semillas se fuman.

[10] Alice Mead hace notar que "reunidas casi simultáneamente en 1893-1894, estas comisiones permitieron al Parlamento desviar la atención de la cuestión real, es decir, el 
en siete volúmenes producto de entrevistas a 1.455 personas en 36 ciudades, llevadas adelante entre 1893 y 1894; es hasta la actualidad uno de los estudios más completos y sistemáticos sobre la marihuana, y no hay casi ningún punto de importancia en las conclusiones que se haya demostrado como erróneo en los más de cien años que han transcurrido desde su publicación (Bewley-Taylor, Blickman y Jelsma, 2014; Zeese, 1999). Entre sus conclusiones se destaca que:

[...] el uso moderado de las drogas del cáńamo no produce prácticamente ningún resultado nocivo. [...] El uso excesivo sí causa daño, pues tiende a poner al consumidor en una situación más vulnerable a la enfermedad [...] la Comisión ha llegado a la conclusión de que su uso moderado no produce ningún efecto perjudicial en la mente. [...] Es distinto en caso de uso excesivo, que estimula la inestabilidad mental. Se ha demostrado que en sujetos con debilidad o predisposición hereditaria el uso excesivo de las drogas del cánamo puede inducir demencia, aunque en este sentido se haya exagerado enormemente de un tiempo a aquí.

[...] Con respecto a los efectos morales de estas drogas, la Comisión es del parecer que su uso moderado no produce lesión moral de ninguna especie. No hay base adecuada para suponer que afecta peligrosamente el carácter de su consumidor [...]. En lo que se refiere a sus relaciones con la sociedad, sin embargo, incluso el consumidor excesivo de drogas del cáńamo es ordinariamente inofensivo (Escohotado, 1998: 354-355).

En consecuencia, la Comisión recomendó que dada la prevalencia del consumo social y religioso en la India, la prohibición total del cultivo, la fabricación y la venta de drogas de cáñamo no es ni necesaria ni conveniente en consideración de sus efectos comprobados, además de que tal medida llevaría a los consumidores a recurrir a otros estimulantes o estupefacientes que podrían ser más perjudiciales. Se abogó, en cambio, por una política de control y restricción, que buscara acabar con el uso excesivo y restringir el uso moderado dentro de unos límites, que se instrumentara por medio de una tributación adecuada, la limitación del número de establecimientos dedicados a la venta al detalle y la limitación de la cantidad de posesión legal (Bewley-Taylor, Blickman y Jelsma, 2014; Zeese, 1999).

Aunque el cannabis era utilizado en distintos preparados medicinales y estaba incluido en los vademécum, era considerada una sustancia elusiva en

suministro de grandes cantidades de opio por parte del Gobierno británico de la India a China, en violación de la legislación china” (Mead, 2014: 45). 
términos de que los preparados no estaban estandarizados, eran inestables y la respuesta de los pacientes era variable. A diferencia de otros psicotrópicos naturales, sus principios activos -el CBD (cannabidiol) y el THC (tetrahidrocannabinol) - no fueron aislados y sintetizados hasta la década de 1960. ${ }^{[11]}$ Con el despegue de la industria farmacéutica y la posibilidad de disponer de los alcaloides de sus fármacos, tanto médicos como boticarios occidentales abandonaron gradualmente el cánamo (Escohotado, 1998), por tanto "cuando el cannabis fue arrastrado a la controversia sobre la fiscalización de drogas en el ámbito internacional, la profesión médica no se levantó enérgica y sistemáticamente en su defensa" (Mead, 2014: 46).

El cannabis fue formalmente introducido al Régimen Internacional de Fiscalización de Sustancias a través de la Convención Internacional del Opio firmada en Ginebra en 1925; resultado de la presión ejercida por -particularmente- Egipto -según el delegado de ese país el hachís era al menos tan perjudicial como el opio, si no más-, Turquía y Sudáfrica, y el apoyo de los Estados Unidos e Italia. Las disposiciones del tratado establecieron la prohibición de exportar cannabis a países donde fuera ilegal y la exigencia de un certificado de importación para los países que permitían su uso. La Convención solo contemplaba la dimensión transnacional del comercio de cannabis. En otras palabras, "el nuevo régimen de fiscalización no prohibía la producción de cannabis ni el comercio nacional, no imponía medidas para reducir su consumo interno y no solicitaba a los gobiernos que proporcionaran sus cálculos de producción de cannabis al Comité Central Permanente del Opio [...]" como sí se exigía con el opio y la cocaína (Bewley-Taylor, Blickman y Jelsma, 2014: 16).

Entre 1925 y la Convención Única de 1961, Estados Unidos lanzó una campaña tanto a nivel doméstico como internacional de demonización de la sustancia. A nivel interno se vinculó la marihuana a determinados grupos -afroamericanos, hispanos, artistas-, a la criminalidad y la locura; discurso que habilitó a que se sancionara en 1937 la Ley de Tributación de la Marihuana, con la que se prohibía efectivamente el cannabis en el país. A nivel multilateral, ejerció presión a través de la oms para que no se consi-

[11] El свD fue aislado por primera vez en la década de 1940 por Roger Adams y Alexander Todd, en investigaciones paralelas. Propusieron una estructura general de la molécula y durante 25 ańos no se avanzó sobre ella. En 1963 el grupo científico liderado por Raphael Mechoulam de la Universidad Hebrea de Jerusalén aisló el CBD, estableció su estructura y estereoquímica relativa. Al año siguiente, este mismo equipo logró el aislamiento y el esclarecimiento de la estructura del principal componente activo de la marihuana, el THC (Mechoulam y Hanuš, 2002). 
derase si el cannabis tenía algún uso médico justificable (Bewley-Taylor, Blickman y Jelsma, 2014).

De modo que, en 1961, fue casi evidente que el cannabis tuviera que clasificarse dentro de la Lista IV de sustancias más peligrosas y sin valor medicinal. Además, sus extractos y tinturas se colocaron en la Lista I, que limitaba su producción a los fines médicos y científicos. Concluye Alice Mead: "dado que estas sustancias habían sido abandonadas por la profesión médica, este criterio, en aquel momento, parecía prohibir efectivamente su uso" (Mead, 2014: 48).

Una década después con la firma de la Convención sobre Sustancias Sicotrópicas se decidió controlar el principal componente activo del cannabis, el THC, y colocarlo en la Lista I, la más estricta. En la misma lista se incluyó el dronabinol, una formulación farmacéutica del THC (delta-9-tetrahidrocannabinol, $\Delta 9$-THC); luego, en 1987, a pedido de Estados Unidos, comenzó el proceso para trasladarla a la Lista II, proceso que se alcanzaría en 1991. ${ }^{[12]}$ El otro componente importante del cannabis, el CBD, no se sometió a fiscalización (cuadro 4).

Cuadro 4. Fiscalización internacional del cannabis y los cannabinoides

\begin{tabular}{|l|l|l|}
\hline Material & Convención $\mathbf{1 9 6 1}$ & Convención 1971 \\
\hline Resina de cannabis & Lista I y IV & - \\
\hline Extractos y tinturas & Lista I & - \\
\hline THC puro & - & Lista I \\
\hline Dronabinol/ $\triangle 9$-THC & - & Lista ॥ \\
\hline CBD puro & - & No listado \\
\hline $\begin{array}{l}\text { Otros cannabinoides puros } \\
\text { (no tetrahidrocannabinoides) }\end{array}$ & - & No listado \\
\hline
\end{tabular}

Fuente: Elaboración propia a partir de Mead (2014).

[12] Desde 2002 el Comité de Expertos de la oms emprendió una nueva revisión crítica y recomendó trasladar el dronabinol a las listas menos severas ya que esta sustancia es objeto de un uso ilícito muy escaso; sin embargo, su recomendación no ha tenido eco en la Comisión de Estupefacientes de la ONu (Hallam, Bewley-Taylor y Jelsma, 2014). 
Entre fines de la década de 1980 y primera mitad de la siguiente, una sucesiva serie de investigaciones científicas condujo a la identificación del Sistema Cannabinoide Endógeno. Es decir, se asoció que los mamíferos al igual que la planta de cannabis producimos un conjunto de compuestos orgánicos de estructura similar denominados endocannabinoides y que, además, en distintas áreas del cuerpo generamos receptores específicos para diversos cannabinoides. $\mathrm{Al}$ actuar a través de la membrana celular, el sistema endocannabinoide está presente en todo el cuerpo, de modo que regula varias funciones fisiológicas (Russo, 2014). A partir de dicho descubrimiento, el desarrollo de investigaciones sobre los efectos del cannabis para la salud tuvo un gran impulso, lo cual dio lugar a la expansión de políticas de cannabis medicinal en el mundo. Este proceso, a su vez, compelió al Comité de Expertos en Farmacodependencia de la oms a realizar más exámenes sobre la sustancia, los cuales produjeron nuevas recomendaciones sobre la clasificación del cannabis y sus componentes (véase Walsh et al., 2019). [13]

$\mathrm{Si}$ bien en nuestro continente existen políticas que reconocen los usos terapéuticos del cannabis desde 1996 en California y en Canadá desde 2001, los países de América Latina recién comenzaron a considerarlo en la década de 2010. Este proceso fue movilizado por dos vías, una "por arriba" a través de la apertura de varias instancias dentro de la oeA para debatir el problema de las drogas en las Américas, y una vía "por abajo" cuando los ciudadanos de la región comenzaron a utilizar productos a base de cannabis para tratar distintas patologías y condiciones, siendo la epilepsia refractaria en niños el uso más representativo.

Antes de abordar los distintos casos, presentamos el marco teórico que guía esta investigación y la metodología que lo posibilitó.

\section{LA TEORÍA DE LA DIFUSIÓN INTERNACIONAL DE POLÍTICAS}

El proceso mediante el cual la adopción y formulación de una política se propaga entre diferentes países ha sido objeto de estudio de sociólogos, politólogos, internacionalistas y economistas que buscan explicar por qué en determinado momento, en una región geográfica ocurre que se elaboran políticas que comparten sus rasgos centrales (Dobbin, Simmons y Garrett, 2007; Weyland, 2005), dinámica por la cual también a largo plazo se daría

[13] En la carta con fecha 24 de enero de 2019 remitida por el director general de la oms, Tedros Adhanom Ghebreyesus, al secretario general de la onU, se encuentran las conclusiones del Comité de Expertos. Véase Ghebreyesus (2019). 
lo que se conoce como convergencia, es decir, la semejanza global en las políticas.

La difusión internacional de políticas se produce cuando la decisión de un país afecta la probabilidad de que tal decisión se tome en otro, más allá del proceso político interno. Se trata de una dinámica de toma de decisión interdependiente y no coordinada. En palabras de Zachary Elkins y Beth Simmons, "bajo esta concepción, los gobiernos son independientes en el sentido de que elaboran sus propias decisiones sin cooperación o coerción pero interdependientes en el sentido de que afectan las decisiones de otros gobiernos" (Elkins y Simmons, 2005: 35).

La literatura en difusión de políticas ha identificado cuatro mecanismos o formas de explicar cómo es que programas, principios o instituciones se propagan a través de las fronteras: la coerción, el aprendizaje, la competencia y la imitación normativa.

\section{Coerción}

Este mecanismo surge de una relación asimétrica de poder, por medio de la cual el actor dominante -ya sea un país o una organización internacional-impone la adopción de políticas a través de condicionalidades (Osorio y Vergara, 2016). También puede existir coerción sin intención, cuando el poderoso influencia unilateralmente las decisiones de un gobierno al cambiar la naturaleza del statu quo que este enfrenta. Asimismo, sin ejercer necesariamente el poder físico ni alterar las relaciones costo-beneficio se impone a través de ideas dominantes que moldean cómo los decisores conceptualizan sus problemas y hallan potenciales soluciones (Dobbin, Simmons y Garrett, 2007).

\section{Aprendizaje}

Este mecanismo supone que cuando los funcionarios de un país desean llevar adelante una política en alguna materia aún no experimentada o que pretenden mejorar, mapean el entorno internacional en búsqueda de las respuestas más óptimas. En otras palabras, se aprende de observar lo que ha funcionado y no de una determinada política en otro lugar. Cabe destacar que la literatura sobre este mecanismo se divide en autores que conciben a los funcionarios con "racionalidad completa" y los que consideran que estos tienen "racionalidad limitada" (Meseguer y Gilardi, 2008; Osorio 
y Vergara, 2016). Los exponentes del primer grupo estiman que los políticos recolectarán datos para realizar un análisis sistemático y exhaustivo de costo-beneficio para comparar las políticas establecidas, y así escoger aquella que maximiza su utilidad. Para los investigadores del segundo grupo, en la evaluación de las políticas los funcionarios utilizan atajos cognitivos y normativos que facilitan el procesamiento de gran cantidad de información, lo cual genera distorsiones o sesgos (Elkins y Simmons, 2005; Weyland, 2005).

\section{Competencia}

Este mecanismo se identifica sobre todo con la difusión de medidas económicas, hace referencia a que la política de un país para favorecer sus exportaciones, atraer inversiones, préstamos, etc., obtendrá ventajas que presionarán a otros estados a realizar algún movimiento similar para no "perder". Algunos autores interpretan que se trata de una coerción descentralizada donde es el mercado el que impone las sanciones y empuja a la convergencia (Dobbin, Simmons y Garrett, 2007; Elkins y Simmons, 2005; Meseguer y Gilardi, 2008).

\section{Imitación normativa}

Este mecanismo también es conocido como emulación o difusión normativa, y coloca el acento en la adopción de políticas por parte de los funcionarios para obtener reputación y legitimidad al copiar modelos de países modernos o para ajustarse a pautas valoradas internacionalmente. Dobbin, Simmons y Garrett (2007) consignan que algunos autores han encontrado evidencia de la firma de tratados internacionales por estados que no tienen la voluntad de ponerlos en práctica. Como indican Marsh y Sharman, "un gobierno puede saber bien que la política en cuestión es técnicamente inefectiva, sin embargo, asigna un mayor valor a las utilidades sociales frente a las audiencias nacionales y extranjeras" (Marsh y Sharman, 2009: 272).

Si bien los mecanismos se han presentado aquí analíticamente separados, en la observación empírica de difusión de políticas se suelen encontrar características de más de uno, o se dificulta conocer exactamente las motivaciones de los funcionarios al adoptar una política. También es posible que en un proceso de difusión operen más de un mecanismo (Osorio y Vergara, 2016). 


\section{METODOLOGÍA}

En este trabajo se aborda la difusión de las políticas de cannabis medicinal en América Latina a partir de un análisis cualitativo situado en tiempo y espacio de fuentes primarias como son las leyes, debates parlamentarios y otros documentos oficiales elaborados durante el proceso de formulación y adopción de la legislación de un $N$-mediano de casos.

Si bien los países que han aprobado políticas de cannabis medicinal en América Latina y el Caribe entre 2015 y 2017 son ocho, Argentina, Chile, Perú, Paraguay, Colombia, México, Jamaica y Puerto Rico, en la investigación se han excluido los países caribeños por un criterio de pertenencia cultural y sociopolítica. ${ }^{[14]}$ Además, se ha dejado de lado la situación del cannabis medicinal en Uruguay dado que se enmarca en la regulación integral de la sustancia en la ley 19.172 (Poder Ejecutivo Uruguay, 2014), ${ }^{[15]}$ situación que ha presentado particularidades y debates sobre el asunto distintos al resto de los países. ${ }^{[16]}$

\section{EL PROCESO DE DIFUSIÓN DE LAS POLÍTICAS DE CANNABIS MEDICINAL}

\section{El pionero: el caso chileno}

En Chile el desarrollo del cannabis medicinal avanzó por tres carriles: el Poder Ejecutivo, el Congreso y la sociedad civil. En febrero de 2005 se promulgó la ley 20.000 que sanciona el tráfico ilícito de estupefacientes y sustancias sicotrópicas, y se consignó en su artículo 63 que un reglamento

[14] Es importante reconocer los límites de este trabajo. Uno refiere a la temporalidad, se trata de innovaciones políticas recientes y los estudios sobre políticas públicas suelen tomar en consideración procesos de más larga duración, es por este motivo que hemos excluido del análisis las reglamentaciones de las leyes ya que estas son aún más recientes. Otra cuestión es la escasa disponibilidad de estudios de cada uno de los casos, quizás antes de hacer una comparación sería necesario tener un conocimiento más profundo del proceso político doméstico de cada país, incluyendo entrevistas a los principales involucrados.

[15] Véase en particular el art. 5, inc. a.

[16] En enero de 2020 fue publicada la ley 19.847 de Acceso al Cannabis Medicinal y Terapéutico (Poder Ejecutivo de Uruguay, 2020) que contempla, entre otras cuestiones, las formulaciones magistrales. Además, en el art. 18 se modifica el art. 5 de la ley 19.172 habilitando transitoriamente las Asociaciones de Pacientes de Cannabis Medicinal, es decir, un cultivo colectivo que deberá contar con un médico tratante y un químico farmacéutico. Como se verá al examinar los casos, en ningún país se permiten estas vías de acceso. 
señalaría las sustancias y especies vegetales que serían consideradas por el primer artículo de esa misma norma como "productoras de dependencia física o síquica, capaces de provocar graves efectos tóxicos o daños considerables a la salud" (Gobierno de Chile, 2005). El reglamento elaborado por el Ministerio del Interior y publicado en febrero de 2008, catalogó dentro de este tipo al cannabis, cualquiera que fuese el nombre con que se designe (Ministerio del Interior de Chile, 2008). Era el primer mandato de Michelle Bachelet y, por primera vez desde 1973, la marihuana se clasificaba a nivel nacional como una sustancia peligrosa.

En julio y agosto de 2014 se presentaron en la Cámara de Diputados dos proyectos que buscaron "legalizar el autocultivo de cannabis para el consumo privado" (Rubilar, Browne y Godoy, 2014) y "despenalizar expendio y autocultivo de cannabis con fines medicinales" (Arriagada et al., 2014), respectivamente. Ambos se fundieron y el nuevo proyecto avanzó en el trámite parlamentario hasta recibir el 7 de julio de 2015 la aprobación en lo general, pero como la propuesta fue objeto de indicaciones volvió a la Comisión de Salud. ${ }^{[17]}$

También en 2014 surgió la Fundación Daya, una organización sin fines de lucro que con el respaldo del alcalde de la comuna de La Florida, Rodolfo Carter, así como el apoyo de la Fundación Arturo López Pérez -institución especializada en el tratamiento del cáncer-, la Farmacopea Chilena y la Universidad de Valparaíso, solicitó el 23 de mayo de ese año al Servicio Agrícola y Ganadero (SAG) autorización para sembrar cannabis y llevar adelante la ejecución del estudio denominado "Uso compasivo de aceite de cannabis como terapia complementaria para el manejo del dolor en usuarios de establecimientos de salud y de Fundación Daya en la comuna de La Florida", la cual se otorgó el 8 de septiembre (Servicio Agrícola y Ganadero de Chile, 2014).

En 2015, durante su segundo mandato, Michelle Bachelet a través del decreto 84 adecuó la normativa vigente "con el objeto de permitir el uso de cannabis y sus derivados para fines de investigación científica o clínica y en tratamientos médicos" (Ministerio de Salud de Chile, 2015). ${ }^{[18]}$ En este

[17] Este proyecto perdió el apoyo de la sociedad civil y de parte de los legisladores que lo promovieron cuando recibió del Poder Ejecutivo indicaciones para bajar la cantidad permitida de seis plantas y diez gramos de cannabis que contenía la propuesta original a una planta y dos gramos (Presidencia de Chile, 2015).

[18] Es importante indicar que Chile ha incorporado los listados de Naciones Unidas a través de tres listas, una del Ministerio del Interior que reglamenta la ley 20.000 sobre represión del narcotráfico (Ministerio del Interior de Chile, 2008), y otras dos que datan de la dictadura y regulan los medicamentos. Sobre estos dos, los decretos 404 y 405 del 
marco, el proyecto de la Fundación Daya se expandió con nuevas solicitudes al sAg. En abril de 2016 se entregó al laboratorio Knop la cosecha de 6.900 plantas -la más grande de Latinoamérica hasta ese momento-, con las cuales elaboró el primer fitofármaco a partir de cannabis, "Cannabiol", mismo que se adjudicó a los beneficiarios del convenio firmado entre la Fundación, el laboratorio y 15 municipios (La Prensa Austral, 2018).

Como se aprecia, el camino chileno fue sinuoso, situación similar ocurrió en Colombia.

\section{Colombia: en busca de oportunidades económicas}

El proceso que dio como resultado la ley 1.787 del 6 de julio de 2016 (Gobierno de Colombia, 2016), se inició con la presentación el 2 de septiembre de 2014 del Proyecto de Ley No 80 del senador Juan Manuel Galán Pachón del Partido Liberal (Congreso de la República de Colombia, 2014a).

En el marco de la Primera Ponencia, llevada a cabo el mes siguiente, el senador relata que viajó junto con otros cuatro senadores y el viceministro de Justicia para conocer la implementación de la regulación de la marihuana medicinal en Colorado, y resaltó que el Departamento de Hacienda de dicho Estado había recaudado más de treinta millones de dólares en el primer semestre de 2014. También un senador de otro partido narra -en el Foro Uso Medicinal de la Marihuana: Del Mito a la Evidencia- que "su primera aproximación al tema fue con bastante escepticismo, luego de conocer la experiencia mencionada cambió sus ideas" (Congreso de la República de Colombia, 2014b: 13).

El primer debate fue aprobado, sin embargo el segundo fue aplazado por la propia bancada liberal por no contar con los apoyos suficientes. El proceso legislativo se retomaría recién en septiembre de año siguiente, no obstante el Poder Ejecutivo emitiría un decreto para acelerar los tiempos: "en medio de la incertidumbre y ante la necesidad de mostrar que el discurso de [el presidente Juan Manuel] Santos sobre un cambio en la política internacional contra las drogas iba acompañado por reformas dentro del país, el Ejecutivo decidió avanzar en la elaboración del decreto" (Garzón y Bernal, 2016). Este fue promulgado el 22 de diciembre de 2015 (Ministerio de Salud de Colombia, 2015).

Ministerio de Salud, es que se hicieron las modificaciones (Ministerio de Salud de Chile, 1984a, 1984b). 
Durante 2016, el debate se dio en la Cámara de Representantes, y en junio, a pocos días de aprobarse la norma, en el marco habilitado por el decreto así como por la Resolución 1.816 del Ministerio de Salud y Protección Social (Ministerio de Salud de Colombia, 2016), fueron otorgadas tres licencias sin costo - dos de las cuales fueron para empresas extranjeras-, lo cual provocó la indignación de los legisladores. Las empresas tuvieron un período de transición de un año para ajustarse al marco establecido por la ley 1.787 .

$\mathrm{Si}$ bien durante las ponencias los legisladores mencionaron modelos extranjeros como el de Holanda o España, e incluso en la Cámara de Representantes se revisó la legislación de la región, lo que primó en Colombia fue la posibilidad de recaudación. En el marco del debate, la Plenaria del Senado aprobó una moción que prohibía la importación del cannabis y sus derivados para fines médicos y científicos, salvo que existiera imposibilidad de su producción en el territorio nacional al tiempo que se promovía la transferencia tecnológica necesaria para la producción nacional. En palabras de la senadora que hizo la propuesta, "se garantiza que por lo menos el negocio que se abre con su producción le quede al país, que ha perdido tanto para llegar a este momento de la historia" (La FM, 2015).

El eje salud versus negocio es uno de los que atravesaron las discusiones sobre cannabis medicinal en América Latina. Otro eje que moldeó los debates fue el de uso terapéutico versus uso recreativo que impactó en el alcance de la legislación resultante en casos como el de Argentina y México que se abordan a continuación.

\section{La Argentina, un cambio insuficiente}

En marzo de 2017, a través de un rápido proceso legislativo, se aprobó la ley 27.350 que regula la "Investigación médica y científica del uso medicinal de la planta de cannabis y sus derivados" (Gobierno de Argentina, 2017).

$\mathrm{El}$ caso argentino estuvo fuertemente influenciado por el chileno. El proceso se inició cuando un grupo de madres de niños con epilepsia refractaria -es decir, un tipo de esta enfermedad del sistema nervioso que no responde a los tratamientos médicos convencionales- viaja a Chile para formarse en la elaboración de aceite de cannabis con la organización sin fines de lucro Mamá Cultiva -aliada de Fundación Daya-. Al regresar, a inicios de 2016, estas madres decidieron agruparse bajo el mismo nombre y empezaron una campaña por la regulación del cannabis medicinal. Si bien 
ya existían grupos de usuarios medicinales, el fenómeno adquirió visibilidad con los testimonios de este grupo en los medios de comunicación (Labiano, 2018).

En junio se reunieron la Comisión de Acción Social y Salud Pública de la Cámara de Diputados, donde se consideraban varios proyectos. Lo que se buscaba era modificar la actual ley 23.373 sobre estupefacientes, dado que muchas de las actividades realizadas por las madres son consideradas delitos a la luz de tal norma.

En noviembre se realizó el debate en la plenaria, las experiencias internacionales estuvieron en el centro de las argumentaciones, se hizo alusión a distintos modelos, como el de Canadá, Israel o Estados Unidos, aunque particular impacto tuvieron las experiencias de los países limítrofes, Chile y Uruguay; también se mencionó a Colombia, que "con todos los problemas de narcotráfico que hemos conocido, lo tienen reglamentado, no tienen miedo y saben que van por carriles diferentes" (Cámara de Diputados de Argentina, 2016). En ese marco, un grupo de legisladores expuso sobre su viaje a Chile:

Mantuvimos diversas reuniones en las que nos interiorizamos sobre lo que hicieron nuestros colegas chilenos al modificar la ley 20.000, por medio de la cual se permite el cultivo de cannabis para uso medicinal. Hoy en Chile hay 200.000 usuarios de aceite de cannabis que han mejorado su calidad de vida. Se trata no solo de nińos sino también de adultos que padecen diversas patologías (Cámara de Diputados de Argentina, 2016).

La Comisión de Acción Social y Salud Pública no fue la única donde se radicaron proyectos, algunos diputados lo hicieron teniendo como cabeceras otras comisiones como Legislación Penal y Seguridad Interior. Esta última, que respondía en su línea política al Ministerio de Seguridad y su visión prohibicionista, logró el dictamen de mayoría. En consecuencia, las principales demandas de las organizaciones que buscaban la regulación del cannabis medicinal -el autocultivo, el cultivo colectivo y el cultivo solidario- no se incluyeron para su tratamiento y aprobación por el pleno de los diputados (Labiano, 2018). Finalmente, en marzo de 2017 se sancionó por unanimidad en la Cámara de Senadores la ley 27.350, que crea el "Programa Nacional para el Estudio y la Investigación del Uso Medicinal de la Planta de Cannabis, sus derivados y tratamientos no convencionales, en la órbita del Ministerio de Salud" (Gobierno de Argentina, 2017).

En el caso argentino ganó la posición que consideraba que establecer el autocultivo de cannabis medicinal abría la puerta al cultivo para uso recrea- 
tivo. Esta situación atraviesa al caso mexicano, donde también fue fuerte el eje de debate sobre fracaso del prohibicionismo versus reformas a las políticas de drogas.

\section{El caso mexicano: "una reforma chiquitita, para un problema enorme"}

Los antecedentes más recientes de la regulación del cannabis medicinal en México los podemos ubicar en la sentencia de la Suprema Corte de Justicia, emitida en noviembre de 2015, sobre el autocultivo para uso recreativo de cuatro adultos (Suprema Corte de Justicia de México, 2014). No obstante que la decisión no tuvo efectos generales, ya que eran necesarios otros cuatro amparos similares con votación favorable, el impacto en el sistema político fue inmediato: seis días después, el presidente instruyó un debate nacional. La discusión se llevó adelante a través de cinco foros en distintas ciudades del país entre enero y abril de 2016. Las conclusiones de estos sirvieron como insumo para el discurso y diez propuestas que presentó el presidente Enrique Peña Nieto el 19 de abril en la Sesión Especial de Naciones Unidas sobre Drogas (UnGass).

En consecuencia, dos días después el mandatario envió a diversas comisiones del Senado una iniciativa para aumentar la portación no punible de cannabis de 5 a 28 gramos y regular sus usos médicos y científicos. La primera parte de la propuesta fue dejada de lado y el dictamen que se trató el 13 de diciembre de 2016 en la plenaria solo versó sobre el uso medicinal, terapéutico, de investigación y científico de derivados químicos del cannabis.

Es importante destacar que este debate se dio al mes siguiente de las elecciones presidenciales en Estados Unidos que sumaron cuatro estados a la legalización del uso recreativo de la marihuana; además, en junio de ese año el primer ministro de Canadá había expresado su intención de legalizar la sustancia en su país, de modo que desde el Río Bravo hasta Alaska toda la costa oeste de América del Norte quedaría con un régimen de marihuana legal. Tanto internas como externas, las presiones por una reforma se hacían sentir sobre los legisladores.

A pesar de tales presiones, el dictamen que dio como resultado el decreto por el que se reforman y adicionan diversas disposiciones de la Ley General de Salud y del Código Penal Federal (Congreso General de los Estados Unidos Mexicanos, 2017), fue considerado por muchos legisladores como "una reforma chiquitita, para un problema enorme", o que "no hace más que reflejar la resistencia al cambio, demostrar que vamos a una 
velocidad mucho más lenta a pesar de que tenemos costos gravísimos", en otras palabras, "difícilmente el Senado estará a la altura de las circunstancias que nos plantea el mundo y, sobre todo, la región de Norteamérica" (Cámara de Senadores de México, 2016). En efecto, en el debate mexicano pesó que los principales socios del país, con quienes tiene un tratado de libre comercio, han regulado el cannabis medicinal desde 1996 en California y desde 2001 en Canadá.

Esa sensación de los legisladores de "quedarse atrás" de sus vecinos también estará presente en el debate peruano que se expone a continuación.

\section{Perú: "¿por qué tenemos que estar siempre detrás de Chile?, por Dios"}

$\mathrm{Al}$ igual que en México, el proceso que dio origen a la ley 30.681 "Que regula el uso medicinal y terapéutico del cannabis y sus derivados" (Gobierno de la República de Perú, 2017) se inició con un proyecto que el Poder Ejecutivo envió para que fuese considerado por el Congreso de la República con carácter de urgente el 22 de febrero de 2017. El documento contó con tres artículos mediante los cuales se autorizaba la importación y comercialización con fines medicinales de productos provenientes del cannabis, proponía además que dos años después se evaluara esta medida y en caso de ser pertinente se autorizara la elaboración nacional de tales productos (Congreso de la República de Perú, 2017). También incorporaba una disposición complementaria mediante la cual se modificaba el artículo del Código Penal que despenaliza el consumo personal, extendiendo la no punibilidad a "la posesión de derivados de la marihuana con fines medicinales, siempre que la cantidad sea la necesaria para el tratamiento de quien la posea o de un tercero que se encuentre bajo su cuidado o tutela" (Congreso de la República de Perú, 2017); esta regla fue incluida en la ley sancionada.

El proyecto de ley fue turnado a dos comisiones, la de Salud y Población y la de Defensa Nacional, Orden Interno, Desarrollo Alternativo y Lucha contra las Drogas. En ellas también se tuvieron en cuenta para la elaboración de sus dictámenes otros cuatro proyectos de ley presentados por congresistas de varias fuerzas políticas, de manera que el proceso legislativo enriqueció y superó la propuesta presidencial que solo consistía en la importación y comercialización de productos derivados del cannabis. Finalmente, el 19 de octubre de 2017 se da el debate en el Congreso.

Habiéndose aprobado regulaciones en la materia en Chile, Colombia, la Argentina y México, el caso peruano muestra la premura por no "quedarse atrás" en la región: 
En la Comisión de Defensa, [...] hubo un intenso debate, porque todavía hay algunos prejuicios con relación al uso medicinal, que ya desde 1960 se da en Israel y desde hace 20 ańos en 29 estados de los Estados Unidos; y, como siempre, nosotros a la zaga. Ahora, el que lidera la investigación en América Latina es Chile, que lo autorizó hace dos ańos; recientemente lo han hecho Uruguay, Colombia, México, Argentina. [...]

Ojalá que en dos o tres años revisemos la norma y podamos liderar en la investigación. ¿’Por qué tenemos que estar siempre detrás de Chile?, por Dios (Congreso de la República de Perú, 2017: 72; énfasis agregado).

Al igual que Perú, Paraguay también tendrá muy presente a la hora de legislar la experiencia de su vecino del sur, la Argentina.

\section{Paraguay: el debate en el principal productor de cannabis de América del Sur}

El proceso legislativo en el último país de la región en regular el uso medicinal del cannabis se inició con un proyecto de la Cámara de Senadores con fecha 10 de mayo del 2017. Allí avanzó hasta lograr la media sanción y el proyecto fue enviado a Diputados, que lo rechazó "invocando como fundamento que el texto aprobado en la Cámara de Senadores, dista en forma considerable de los fundamentos expuestos en la exposición de motivos", esto porque se proponía la "despenalización del cannabis para uso medicinal", lo cual no era necesario; si bien el texto se modificó, la alusión no fue quitada de la exposición de motivos. ${ }^{[19]}$ En paralelo, en la Cámara de Diputados se trataba otro proyecto ingresado el 21 de junio de 2017. A este se adicionaron algunos artículos del proyecto de senadores previamente rechazado. El trámite parlamentario en esta cámara se resolvió en cinco meses, pasó al Senado y este lo aprobó el 5 de diciembre.

Llama la atención el parecido de la norma resultante, la ley 6.007 (Congreso de la Nación de Paraguay, 2017), con su homóloga de la Argentina, la ley 27.350. El artículo $1^{\circ}$, el $2^{\circ}$, el $5^{\circ}$, el $7^{\circ}$ y el $8^{\circ}$ son similares; si se observan los proyectos que le dieron origen -tanto la propuesta

[19] Como indicó uno de los autores del proyecto: "En las mesas de trabajo y en las audiencias públicas realizadas, quedó demostrado que tenemos dos convenios vigentes al respecto que nos autorizan ya a hacerlo, entonces, no necesitábamos despenalizar, modificamos el artículo $1^{\circ}$ del proyecto, lo enriquecimos pero nos olvidamos de sacar la despenalización de la exposición de motivos" (Paraguay - Cámara de Senadores, 2017). 
de los senadores Ramón Gómez Verlangieri, Blas Llano y Fernando Silva Facetti (Gómez Verlagieri, Llano y Silva Facetti, 2017) como la del Diputado Eber Ovelar Benítez (Ovelar Benítez, 2017)-, son casi iguales, proponiendo un Consejo Consultivo Honorario que, finalmente, no fue incluido en la legislación. Quedará para futuros estudios conocer por qué tomaron como inspiración la ley argentina y no otra.

Sin embargo, a diferencia de su vecino del sur, Paraguay ya sacó a la venta el primer fitofármaco sobre la base de cannabis de industria nacional. El laboratorio Lasca es el único que cuenta en el país con permiso para importar cristales de cannabidiol -uno de los principales componentes de la planta- que luego convierte en aceite que se vende en presentaciones de $25 \mathrm{mg}$ (Ministerio de Salud y Bienestar Social de Paraguay, 2018).

\section{LAS POLÍTICAS DE CANNABIS MEDICINAL A TRAVÉS DE LA DIFUSIÓN INTERNACIONAL}

Después de exponer los casos cronológicamente, podemos abordarlos desde la perspectiva teórica escogida: la difusión internacional de las políticas públicas. Recordemos el primer mecanismo, coerción sugiere que un actor dominante -ya sea un país o una organización internacional- impone la adopción de políticas a través de condicionalidades. Los datos no dan cuenta de que esta forma haya operado en la difusión de las políticas de cannabis medicinal en América Latina.

Tampoco la evidencia indicaría que los decisores hayan mapeado el entorno internacional en búsqueda de las respuestas más óptimas como sostiene el mecanismo de aprendizaje, lo cual se hace notorio dada la temporalidad en la que ocurrió la difusión (2015-2017). Circunstancia que destacó Kurt Weyland: "el corto lapso durante el cual muchos países adoptan un modelo poco después de su primera aparición, se desvía del aprendizaje racional, que requiere un análisis cuidadoso de costo-beneficio que implica una trayectoria más larga" (Weyland, 2005: 280).

Respecto del mecanismo de competencia, el cual hace referencia a que la política de un país para favorecer sus exportaciones, atraer inversiones, préstamos, etc. obtendrá ventajas que presionarán a otros estados a realizar algún movimiento similar para no "perder", es una idea presente en el continente latinoamericano en el cual todos los países tienen capacidades para la producción a gran escala de la planta. Quizás el caso más evidente donde se pretendió generar una ventaja competitiva es Colombia, que incluyó en su ley cláusulas como "el Estado deberá diseñar los mecanismos mediante 
los cuales se implementarán las iniciativas económicas de producción, transformación y distribución de productos derivados de la planta de cannabis", o "en la reglamentación y expedición de licencias debe protegerse la industria e iniciativas nacionales" y un sistema de cobro "por los servicios de evaluación y seguimiento a los solicitantes o titulares de las licencias" (Gobierno de Colombia, 2016). También como se mencionó, fue notoria la premura del Ejecutivo por otorgar las primeras licencias a dos compañías líderes del mercado internacional del cannabis medicinal. Sin embargo, dicha racionalidad económica no parece haber calado en la adopción de este tipo de políticas en el resto de los países; el "no quedarse atrás" fue más bien normativo que económico.

En otras palabras, los datos con los que contamos apuntan a que el mecanismo que operó en la difusión de políticas de cannabis medicinal en América Latina fue la imitación, emulación o difusión normativa, según el cual los funcionarios adoptan ciertas políticas para obtener reputación y legitimidad al copiar modelos de países modernos o para ajustarse a pautas valoradas internacionalmente. Las legislaciones sobre cannabis pueden entenderse como políticas distributivas -en la clásica acepción de Löwi-, esto es, aquellas donde los costos sociales están distribuidos y los beneficios concentrados (Löwi, 1972). Es decir, los programas que se establecieron con estas leyes no implicarían grandes costos económicos ni políticos, y beneficiarían a un grupo particular del conjunto social, los usuarios de cannabis medicinal. Como identifica Weyland: "las decisiones distributivas son políticamente atractivas porque hacen a algunos votantes felices pero no dejan a nadie satisfecho. Entonces, las decisiones distributivas son fácilmente incentivadas por motivos normativos o simbólicos" (Weyland, 2005: 276).

\section{COMENTARIOS FINALES}

En el presente trabajo se buscó dar respuesta a las siguientes preguntas respecto de las políticas de cannabis medicinal en América Latina: ¿estamos frente a lo que la ciencia política identifica como difusión de políticas?; ¿a través de qué mecanismos se produjo?; ¿por qué en esa temporalidad?; ¿qué experiencias de otros países se tuvieron en cuenta? El propósito central que se planteó fue realizar una primera aproximación a este fenómeno, a fin de aportar a la literatura sobre adopción de políticas de cannabis medicinal, la cual es escasa a nivel mundial y casi inexistente para América Latina. 
En el desarrollo dimos cuenta genealogía del Régimen Internacional de Fiscalización de Sustancias y el tratamiento que le da al cannabis. También se propuso un enfoque teórico desde el cual examinar este objeto, la difusión internacional de políticas. Repasamos los seis casos y consideramos que los datos indicarían que se trató de una difusión normativa de estas políticas.

El debate de las políticas de cannabis en cada uno de estos países estuvo atravesado por evitar "legalizar el uso recreativo de la planta". Los legisladores se esforzaron por poner "candados" para que la sustancia no se desviase para otros propósitos, e incluso algunas posiciones -como la del expresidente colombiano Álvaro Uribe- sostenían que "legalizar el uso terapéutico de la marihuana es abrir el camino para otros fines" (Castañeda, 2015). En efecto, ninguna de las legislaciones optó por mecanismos como el autocultivo medicinal, el cultivo colectivo, cultivo solidario o expendio herbal como ocurre en diversas jurisdicciones en el mundo, tal como relevó el artículo "Mapping regulatory models for medicinal cannabis: a matrix of options" (Belackova, Shanahan y Ritter, 2018).

Otra cuestión que marcó el debate fue lo "ilógico" de importar a altos costos medicamentos u otros productos derivados del cannabis que podrían ser producidos en la región a mucho menor precio.

Finalmente, no podemos dejar de mencionar la contradicción que muchos observaron respecto de que el poderoso país que impuso la "guerra contra las drogas" está legalizando la sustancia en su territorio y que en nuestra región nos empeñemos en sostener el prohibicionismo que tantas consecuencias negativas ha generado. Como se abogó en la justificación de un proyecto de ley: "Basta citar algunos ejemplos de países como los Estados Unidos de Norteamérica que por décadas ha ejercido una presión bastante fuerte en contra de la producción y el consumo de esta droga y que hoy sin embargo va cambiando su política respecto a ella, no solo en el uso medicinal sino en el recreativo" (Gómez Verlangieri, Llano y Silva Facetti, 2017).

Por último, para futuras investigaciones quedará explorar la relación entre normas internacionales y nacionales, ya que el hecho de que más países se integren a la "ola" del cannabis medicinal es uno de los motivos que llevó a la Organización Mundial de la Salud a realizar exámenes previos del cannabis y de las sustancias que lo componen para evaluar si mantiene la planta dentro las listas I y IV de sustancias controladas por las Convenciones de Naciones Unidas (Naciones Unidas, 1961, 1971, 1988). 


\section{REFERENCIAS BIBLIOGRÁFICAS}

Arriagada, C. et al. (2014), "Proyecto de Ley. Modifica Código Sanitario y ley $\mathrm{N}^{\circ} 20.000$, que Sanciona el Tráfico Ilícito de Estupefacientes y Sustancias Sicotrópicas, con el objeto de despenalizar expendio y autocultivo de cannabis con fines medicinales", Boletín 9.496-11, 7 de agosto. Disponible en: $<$ https://www.camara.cl/verDoc.aspx?prmID=9711\&prmTIPO= INICIATIVA $>$.

Belackova, V., M. Shanahan y A. Ritter (2018), "Mapping regulatory models for medicinal cannabis: a matrix of options", Australian Health Review, vol. 42, No 4, pp. 403-411.

Bewley-Taylor, D. y M. Jelsma (2011), Cincuenta años de la Convención Única de 1961 sobre Estupefacientes: Una relectura crítica, Serie Reforma Legislativa en Materia de Drogas No 12, Transnational Institute (TNI). Disponible en: $<$ https://www.tni.org/files/download/dlr12s.pdf>.

__ y T. Blickman (2014), Auge y caida de la prohibición del cannabis, Ámsterdam y Swansea, Transnational Institute (TNI) / Global Drug Policy Observatory (GDPO).

Cámara de Diputados de Argentina (2016), 21 a Reunión de Diputados 20a Sesión Ordinaria (Especial), Uso Medicinal de la Planta de Cannabis $y$ sus Derivados, versión taquigráfica, 23 de noviembre. Disponible en: <https://www4.hcdn.gob.ar/dependencias/dtaquigrafos/diarios/ periodo-134/134-11-23.pdf>.

Cámara de Senadores de México (2016), "Proyecto de Decreto por el que se Reforman y Adicionan Diversas Disposiciones de la Ley General de Salud y del Código Penal Federal, en Materia de Regulación y Uso de la Marihuana", Diario de Debate de Senadores, LXIII Legislatura, Segundo Año de Ejercicio Primer Período Ordinario, 13 de diciembre.

Cámara de Senadores de Paraguay (2017), "Sesión extraordinaria 235", versión taquigráfica, Diario de Sesiones, No 235, 5 de diciembre. Disponible en: $<$ http://silpy.congreso.gov.py/descarga/sesion-109071>.

Carrillo, D. (2013), A growing trend: policy diffusion of medical marijuana laws in the American States, Master of Arts in Political Science, San Diego, San Diego State University.

Carstairs, C. (2005), "The stages of the international drug control system", Drug and Alcohol Review, vol. 24, No 1, pp. 57-65.

Castañeda, O. (2015), "Legalizar uso Terapéutico de la Marihuana es abrir el camino para otros fines", Prensa Centro Democrático. Disponible en: $<$ http://www.senado.gov.co/component/k2/item/23228-legalizar-el-uso- 
terapeutico-de-la-marihuana-es-abrir-el-camino-de-su-consumo-paraotros-fines-senador-castaneda>.

Congreso de la Nación de Paraguay (2017), "Ley No 6.007. Que crea el Programa Nacional para el Estudio y la Investigación Médica y Científica del Uso Medicinal de la planta de Cannabis y sus derivados", Gaceta Oficial, No 249, 29 de diciembre, pp. 28-32. Disponible en: <http://www.gacetaoficial.gov.py/index/getDocumento/50134>.

Congreso de la República de Colombia (2014a), "Proyecto de Ley número 80 de 2014. Senado", Gaceta del Congreso, vol. xxiII, No 456, 2 de septiembre, pp. 4-20. Disponible en: <http://svrpubindc.imprenta.gov.co/senado/ index $2 . x h t m l$ ?ent $=$ Senado\&fec $=2-9-2014 \&$ num $=456>$.

_ (2014b), "Informe de Ponencia para Primer Debate al Proyecto de Ley número 80 de 2014", Gaceta del Congreso, vol. xxiII, No 665, 29 de octubre, pp. 8-19. Disponible en: <http://svrpubindc.imprenta.gov.co/ senado $/$ index $2 \cdot x h t m l$ ent $=$ Senado $\& f e c=29-10-2014 \&$ num $=665>$.

Congreso de la República de Perú (2017), "Primera Legislatura Ordinaria de 2017 16. a Sesión (Matinal)”, Diario de los Debates, 19 de octubre. Disponible en: <http://www.leyes.congreso.gob.pe/Documentos/2016_2021/ADLP/ Diario_Debates/30681-TDD.pdf>.

Congreso General de los Estados Unidos Mexicanos de México (2017), Decreto por el que se reforman y adicionan diversas disposiciones de la Ley General de Salud y del Código Penal Federal, 19 de junio. Disponible en: <http://www. dof.gob.mx/nota_detalle.php?codigo $=5487335 \&$ fecha $=19 / 06 / 2017>$.

Dobbin, F., B. Simmons y G. Garrett (2007), "The Global Diffusion of Public Policies: Social Construction, Coercion, Competition, or Learning", Annual Review of Sociology, No 33, pp. 449-472.

Elkins, Z. y B. Simmons (2005), "On Waves, Clusters, and Diffusion: A Conceptual Framework", The Annals of the American Academy of Political and Social Science, vol. 598, No 1, pp. 33-51.

Escohotado, A. (1998), Historia general de las drogas, Madrid, Alianza Editorial. Garzón, J. y J. Bernal (2016), "Regulación de la marihuana medicinal: sinsabores, dudas y oportunidades”, Razón Pública, 8 de agosto. Disponible en: <https:// razonpublica.org/regulacion-de-la-marihuana-medicinal-sinsabores-dudasy-oportunidades/>.

Ghebreyesus, T. A. (2019), "Letter from Doctor Tedros Adhanom Ghebreyesus to Antonio Guterres, Secretary-General of the United Nations" [Carta a Antonio Guterres], Disponible en: <https://www.who.int/medicines/ access/controlled-substances/UNSG_letter_ECDD41_recommendations_ cannabis_24Jan19.pdf?ua=1\%3e>. 
Gobierno de Argentina (2017), "Ley 27.350. Uso medicinal de la planta de cannabis y sus derivados", Boletin Oficial, vol. cxxv, № 33.607, 19 de abril, pp. 1-3. Dispoinible en: <https://www.boletinoficial.gob.ar/detalleAviso/ primera/162454/20170419>.

Gobierno de Chile (2005), "Ley 20.000. Sustituye la Ley No 19.366, que sanciona el tráfico ilícito de estupefacientes y sustancias psicotrópicas", 2 de febrero. Promulgada el 16 de febrero de 2005. Disponible en: <https:// www.bcn.cl/leychile/navegar?idNorma $=235507>$.

Gobierno de Colombia (2016), "Ley 1787 de 2016", Diario Oficial, vol. cLI, No 49.926, 6 de julio, pp. 1-4. Disponible en: <http://svrpubindc.imprenta.gov.co/diario/>.

Gobierno de la República de Perú (2017), "Ley No 30.681. Ley que regula el uso medicinal y terapéutico del cannabis y sus derivados, El Peruano, 17 de noviembre, pp. 3-4. Disponible en: <http://www.leyes.congreso. gob.pe/Documentos/2016_2021/ADLP/Normas_Legales/30681-LEY. $\mathrm{pdf}>$.

Gómez Verlangieri, R., B. Llano y F. Silva Facetti (2017), Proyecto de Ley "Que Crea el Programa Nacional para el Estudio y la Investigación Médica y Científica de la planta de Cannabis", Expediente: S-177.560. Disponible en: <http://silpy.congreso.gov.py/expediente/109422>.

Hallam, C., M. Jelsma y D. Bewley-Taylor (2014), La clasificación en el sistema internacional de control de drogas, Reforma legislativa en materia de drogas No 25, Transnational Institute (TNI) / International Drug Policy Consortium (IDPC). Disponible en: <https://www.tni.org/files/download/serie_reforma_legislativa_no._25.pdf $>$.

La FM (2015), "Senado prohíbe importación de cannabis y sus derivados con fines medicinales", La FM, 11 de diciembre. Disponible en: <https:// www.lafm.com.co/politica/senado-prohibe-importacion-de-cannabis-ysus-derivados-con-fines-medicinales>.

La Prensa Austral (2018), "Fundación Daya inició entrega de 'Cannabiol' en los 15 municipios con los que suscribió convenio", La Prensa Austral, 2 de abril. Disponible en: <https://laprensaaustral.cl/cronica/fundacion-dayainicio-entrega-de-cannabiol-en-los-15-municipios-con-los-que-suscribioconvenio/>.

Labiano, V. (2018), "Cannabis medicinal en Argentina: cambio menor en el subsistema de política de drogas", Revista Uruguaya de Ciencia Política, vol. 27, No 2, pp. 75-98.

Liga de las Naciones (1931), Convención para limitar la manufactura y regular la distribución de estupefacientes, Ginebra, Liga de las Naciones. Disponible en: $<$ https://www.dipublico.org/9998/convenio-para-limitar-la-manufactura- 
y-regular-la-distribucion-de-estupefacientes-ginebra-13-de-julio-de-1931protocolo-de-firma/>.

Löwi, T. (1972), "Four Systems of Policy, Politics, and Choice", Public Administration Review, vol. 32, No 4, pp. 298-310.

Marsh, D. y J. Sharman (2009), "Policy diffusion and policy transfer", Policy Studies, vol. 30, No 3, pp. 269-288.

McAllister, W. (1991), "Conflicts of Interest in the International Drug Control System", Journal of Policy History, vol. 3, No 4, pp. 143-166.

Mead, A. (2014), "International Control of Cannabis", en Pertwee, R. (ed.), Handbook of Cannabis, Nueva York, Oxford University Press, pp. 44-64.

Mechoulam, R. y L. Hanuš (2002), "Cannabidiol: An overview of some chemical and pharmacological aspects. Part I: chemical aspects", Chemistry and Physics of Lipids, vol. 121, No 1-2, pp. 35-43.

Meseguer, C. y F. Gilardi (2008), "Reflexiones sobre el debate de la difusión de políticas", Politica y Gobierno, vol. 15, No 2, pp. 315-351.

Ministerio de Salud de Chile (1984a), "Decreto 404. Reglamento de Estupefacientes", 20 de febrero, promulgado el 2 de noviembre de 1983. Disponible en: <https://www.bcn.cl/leychile/navegar?idNorma=13057>. (1984b), "Decreto 405. Reglamento de Productos Psicotrópicos", 20 de febrero, promulgado el 2 de noviembre de 1983. Disponible en: <https:// www.bcn.cl/leychile/navegar?idNorma=13066>.

- (2015), "Decreto 84. Modifica los Decretos Supremos No 404 y 405, ambos de 1983, Reglamento de Estupefacientes y Reglamento de Psicotrópicos, respectivamente, ambos del Ministerio de Salud", 7 de diciembre, promulgado el 30 de octubre de 2015. Disponible en: <https:// www.bcn.cl/leychile/navegar?idNorma $=1085003>$.

Ministerio de Salud y Protección Social de Colombia (MinSalud) (2015), "Decreto 2467 de 2015", Diario Oficial, vol. cli, No 49.734, 22 de diciembre, pp. 5-9. Disponible en: <http://svrpubindc.imprenta.gov.co/diario/>.

— (2016), "Resolución número 00001816", Diario Oficial, cLI, No 49.872, 12 de mayo, pp. 3-12. Disponible en: <http://svrpubindc.imprenta.gov.co/ diario/>.

Ministerio de Salud Pública y Bienestar Social de Paraguay (2018), "Primer medicamento elaborado a base de cannabis ya está disponible en el país". Disponible en: <https://www.mspbs.gov.py/portal/15648/primermedicamento-elaborado-a-base-de-cannabis-ya-esta-disponible-en-el-pais. html>.

Ministerio del Interior de Chile (2008), "Decreto 867. Aprueba reglamento de la Ley No 20.000 que sanciona el tráfico ilícito de estupefacientes y sustancias sicotrópicas y sustituye la Ley No 19.366”, 19 de febrero, promul- 
gado el 8 de agosto de 2007. Disponible en: <https://www.bcn.cl/leychile/ navegar?idNorma $=269323>$.

Naciones Unidas (1961), Convención Única sobre Estupefacientes, Ginebra, Naciones Unidas.

— (1971), Convenio sobre Sustancias Sicotrópicas, Viena, Naciones Unidas. (1988), Convención de las Naciones Unidas contra el Tráfico Ilícito de Estupefacientes y Sustancias Sicotrópicas, Nueva York, Naciones Unidas. -(s/f), MultilateralTreaties Deposited with the Secretary-General. Disponible en: $<$ https://treaties.un.org/Pages/Treaties.aspx?id=6\&subid=A\&clang=_en>.

Nadelmann, E. (1990), "Global prohibition regimes: The evolution of norms in international society", International Organization, vol. 44, No 4, pp. 479-526.

Nixon, R. (1971), "Remarks About an Intensified Program for Drug Abuse Prevention and Control", Washington, The American Presidency project. Disponible en: <https://www.presidency.ucsb.edu/node/240238>.

Osorio, C. y J. Vergara (2016), "La difusión de políticas públicas. Estado del arte y contribuciones para la disciplina en América Latina", Politica. Revista de Ciencia Politica, vol. 54, No 2, pp. 235-254.

Ovelar, E. (2017), "Proyecto de Ley 'Que Establece el Marco de Regulación para la Investigación y Uso Medicinal de la Planta de Cannabis y sus Derivados"', Expediente: D-1.744.145. Disponible en: <http://silpy.congreso.gov.py/expediente/109820>.

Pietschmann, T. (2007), "Un siglo de fiscalización internacional de drogas", Boletin de estupefacientes, vol. 59, No 1-2, pp. 1-167.

Poder Ejecutivo de Uruguay (2014), "Ley 19.172", Diario Oficial, vol. cix, No 28.878, 7 de enero, pp. 4-9. Disponible en: <https://www.impo.com.uy/ diariooficial/2014/01/07>. (2020), "Ley 19.847", Diario Oficial, vol. cxv, № 30.353, 8 de enero, pp. 4-9. Disponible en: <https://www.impo.com.uy/diariooficial/2020/01/08>.

Presidencia de la República de Perú (2017), "Ley que autoriza la importación, comercialización y el uso con fines medicinales de productos provenientes del cannabis", Proyecto de Ley 982/2016-PE, 22 de febrero. Disponible en: $<$ http://www.leyes.congreso.gob.pe/Documentos/2016_2021/Proyectos_ de_Ley_y_de_Resoluciones_Legislativas/PL0098220170222..pdf>.

Presidencia de Chile (2015), "Oficio No 997-363. Formula indicaciones al proyecto de ley que modifica Código Sanitario y Ley No 20.000, que sustituye la Ley No 19.366, Que sanciona el tráfico ilícito de estupefacientes y sustancias sicotrópicas, con el objeto de legalizar el autocultivo de cannabis para el consumo privado y despenalizar su expendio y cultivo para fines medicinales (boletines No 9.471-11 y 9.496-11, Refundidos)”, 
1 de octubre. Disponible en: <https://www.camara.cl/verDoc.aspx?prmID $=20583 \&$ prmTIPO $=$ OFICIOPLEY $>$.

Room, R. (2015), "The un Drug Conventions: Evidence on Effects and Impact", en el-Guebaly, N.; G. Carrà y M. Galanter (eds.), Textbook of Addiction Treatment: International Perspectives, Milán, Springer, pp. 1377-1385.

Rubilar, K., P. Browne y J. Godoy (2014), "Proyecto de Ley. Modifica ley No 20.000, sobre Tráfico Ilícito de Estupefacientes y Sustancias Sicotrópicas, con el objeto de legalizar el autocultivo de cannabis para el consumo privado", Boletín 9.471-11, 23 de julio. Disponible en: <https://www. camara.cl/verDoc.aspx?prmID=9684\&prmTIPO=INICIATIVA $>$.

Russo, E. (2014), "The Pharmacological History of Cannabis", en Pertwee, R. (ed.), Handbook of Cannabis, Nueva York, Oxford University Press, pp. 23-43.

Sánchez Avilés, C. (2014), "El Régimen internacional de control de drogas. Formación, evolución e interacción con las políticas nacionales : el caso de la política de drogas de España”, tesis doctoral, Barcelona, Universitat Pompeu Fabra.

Servicio Agrícola y Ganadero de Chile (2014), "Resolución Exenta No 2.490/2014. Autoriza a Fundación Daya la siembra, plantación, cultivo y cosecha de especie cannabis sativa en los términos que indica”, 8 de septiembre. Disponible en: <http://www.fundaciondaya.org/wp-content/ uploads/2015/08/Resolución-de-aprobación-SAG.pdf>.

Sinha, J. (2001), The History and Development of the Leading International Drug Control Conventions, Ottawa, Library of Parliament. Disponible en: <https:// sencanada.ca/content/sen/committee/371/ille/library/history-e.htm>.

Suprema Corte de Justicia de la Nación de México (2015), Amparo en Revisión 237/2014, 4 de noviembre.

Walsh, J. et al. (2019), The WHO's First-Ever Critical Review of Cannabis: A Mixture of Obvious Recommendations Deserving Support and Dubious Methods and Outcomes Requiring Scrutiny, Ámsterdam, Washington Office on Latin America (wOLA) / Transnational Institute (TNI) / Global Drug Policy Observatory (GDPO-Swansea University). Disponible en: <https://www.tni. org/en/publication/the-whos-first-ever-critical-review-of-cannabis>.

Weyland, K. (2005), "Theories of Policy Diffusion: Lessons from Latin American Pension Reform", World Politics, vol. 57, No 2, pp. 262-295.

Zeese, K. (1999), "Marijuana in the $20^{\text {th }}$ century: A chronology of use and regulation", International Journal of Drug Policy, vol. 10, No 4, pp. 339-346.

Artículo recibido el 3 de diciembre de 2019. Aprobado para su publicación el 18 de marzo de 2020. 


\begin{tabular}{|c|c|c|c|c|c|c|}
\hline & Chille & Colombia & Argentina & México & Perú & Paraguay \\
\hline Objeto & $\begin{array}{l}\text { Facilitar el acceso a } \\
\text { tratamientos y } \\
\text { medicamentos } \\
\text { derivados de la } \\
\text { especie vegetal } \\
\text { cannabis sativa; } \\
\text { permitir el uso de } \\
\text { cannabis y sus } \\
\text { derivados para fines } \\
\text { de investigación } \\
\text { científica o clínica y } \\
\text { en tratamientos } \\
\text { médicos. }\end{array}$ & $\begin{array}{l}\text { Permitir el acceso } \\
\text { seguro e informado } \\
\text { al uso médico y } \\
\text { científico del } \\
\text { cannabis y sus } \\
\text { derivados en el } \\
\text { territorio nacional } \\
\text { colombiano. }\end{array}$ & $\begin{array}{l}\text { Establecer un marco } \\
\text { regulatorio para la } \\
\text { investigación } \\
\text { médica y científica } \\
\text { del uso medicinal, } \\
\text { terapéutico y/o } \\
\text { paliativo del dolor } \\
\text { de la planta de } \\
\text { cannabis y sus } \\
\text { derivados, } \\
\text { garantizando y } \\
\text { promoviendo el } \\
\text { cuidado integral de } \\
\text { la salud. }\end{array}$ & $\begin{array}{l}\text { La Secretaría de } \\
\text { Salud deberá diseñar } \\
\text { y ejecutar políticas } \\
\text { públicas que regulen } \\
\text { el uso medicinal de } \\
\text { los derivados farma- } \\
\text { cológicos de la can- } \\
\text { nabis sativa, índica y } \\
\text { americana o mari- } \\
\text { huana, entre los que } \\
\text { se encuentra el } \\
\text { tetrahidrocannabinol, } \\
\text { sus isómeros y } \\
\text { variantes estereoquí- } \\
\text { micas, así como nor- } \\
\text { mar la investigación } \\
\text { y producción nacio- } \\
\text { nal de estos. }\end{array}$ & $\begin{array}{l}\text { Garantizar el } \\
\text { derecho } \\
\text { fundamental a la } \\
\text { salud y permitir el } \\
\text { acceso, } \\
\text { exclusivamente para } \\
\text { uso medicinal y } \\
\text { terapéutico, del } \\
\text { cannabis y sus } \\
\text { derivados. }\end{array}$ & $\begin{array}{l}\text { Promover el estudio } \\
\text { y la investigación } \\
\text { médica y científica } \\
\text { del uso medicinal, } \\
\text { terapéutico y/0 } \\
\text { paliativo de la } \\
\text { planta de cannabis } \\
\text { y sus derivados para } \\
\text { el tratamiento de } \\
\text { enfermedades y } \\
\text { afecciones en } \\
\text { humanos. }\end{array}$ \\
\hline $\begin{array}{l}\text { Modalidad } \\
\text { de acceso }\end{array}$ & $\begin{array}{l}\text { Podrán expenderse } \\
\text { al público en } \\
\text { farmacias } 0 \\
\text { laboratorios } \\
\text { mediante receta } \\
\text { médica retenida con } \\
\text { control de } \\
\text { existencia. }\end{array}$ & $\begin{array}{l}\text { Otorgamiento de } \\
\text { licencias para } \\
\text { importación, } \\
\text { exportación, } \\
\text { producción, } \\
\text { fabricación, } \\
\text { adquisición a } \\
\text { cualquier título, } \\
\text { almacenamiento, } \\
\text { transporte, } \\
\text { comercialización, } \\
\text { distribución y uso } \\
\text { de derivados de } \\
\text { cannabis. }\end{array}$ & $\begin{array}{l}\text { La provisión de } \\
\text { aceite de cannabis y } \\
\text { sus derivados } \\
\text { importados será } \\
\text { gratuita para } \\
\text { quienes se } \\
\text { encuentren } \\
\text { incorporados al } \\
\text { programa. }\end{array}$ & $\begin{array}{l}\text { La Secretaría de } \\
\text { Salud otorgará } \\
\text { autorización } \\
\text { para importar } \\
\text { estupefacientes, } \\
\text { substancias } \\
\text { psicotrópicas, } \\
\text { productos o } \\
\text { preparados que los } \\
\text { contengan, } \\
\text { incluyendo los } \\
\text { derivados } \\
\text { farmacológicos de la } \\
\text { cannabis sativa, } \\
\text { índica y americana. }\end{array}$ & $\begin{array}{l}\text { La producción y el } \\
\text { abastecimiento de } \\
\text { insumos para la } \\
\text { investigación del } \\
\text { cannabis con } \\
\text { fines medicinales y } \\
\text { terapéuticos son de } \\
\text { exclusiva competen- } \\
\text { cia del Poder Ejecu- } \\
\text { tivo, a través del } \\
\text { Ministerio de Salud, } \\
\text { la Dirección General } \\
\text { de Medicamentos, } \\
\text { Insumos y Drogas, el } \\
\text { Instituto Nacional } \\
\text { de Salud. }\end{array}$ & $\begin{array}{l}\text { El Estado promoverá } \\
\text { la producción e } \\
\text { industrialización de } \\
\text { medicamentos } \\
\text { derivados de la } \\
\text { planta de cannabis } \\
\text { en laboratorios de } \\
\text { instituciones } \\
\text { públicas [...]. Esta } \\
\text { producción estará } \\
\text { destinada a } \\
\text { garantizar el acceso } \\
\text { gratuito a pacientes } \\
\text { incluidos en el } \\
\text { registro establecido. }\end{array}$ \\
\hline Sanciones & NO & $\begin{array}{l}\text { Declaración de } \\
\text { condiciones } \\
\text { resolutorias o } \\
\text { suspensión de } \\
\text { licencias; multas; } \\
\text { compulsar copias } \\
\text { de la actuación a la } \\
\text { Fiscalía General de } \\
\text { la Nación. }\end{array}$ & NO & NO & $\begin{array}{l}\text { Mediante resolución } \\
\text { debidamente motiva- } \\
\text { da, suspende o can- } \\
\text { cela la licencia otor- } \\
\text { gada, sin perjuicio } \\
\text { de imponerse concu- } \\
\text { rrentemente las res- } \\
\text { ponsabilidades } \\
\text { administrativas, civi- } \\
\text { les o penales que } \\
\text { correspondan. Será } \\
\text { reprimido con la } \\
\text { pena máxima más el } \\
\text { cincuenta por ciento } \\
\text { de la misma al fun- } \\
\text { cionario público que } \\
\text { otorga irregularmen- } \\
\text { te la licencia. }\end{array}$ & NO \\
\hline $\begin{array}{l}\text { Importación } \\
\text { previa a la } \\
\text { ley }\end{array}$ & $\begin{array}{l}\text { Sí, Sativex (Caso } \\
\text { Cecilia Hyder, } \\
\text { 24/07/2014). }\end{array}$ & $\begin{array}{l}\text { Sí, se concede } \\
\text { registro sanitario al } \\
\text { Sativex } \\
(10 / 10 / 2016) .\end{array}$ & $\begin{array}{l}\text { Sí, Charlotte's web } \\
\text { (caso Josefina } \\
\text { Vilumbrales, } \\
\text { noviembre de } \\
\text { 2015). }\end{array}$ & $\begin{array}{l}\text { Sí, Charlotte's web } \\
\text { (caso Grace Elizalde, } \\
\text { septiembre de } \\
\text { 2015). }\end{array}$ & NO & $\begin{array}{l}\text { Sí, RSH0 Liquid } \\
1.000 \text { mg Blue } \\
\text { (para Mathias } \\
\text { Alejandro González, } \\
\text { abril de 2016). }\end{array}$ \\
\hline
\end{tabular}




\begin{tabular}{|c|c|c|c|c|c|c|}
\hline & Chile & Colombia & Argentina & México & Perú & Paraguay \\
\hline Registros & NO & NO & $\begin{array}{l}\text { Registro nacional } \\
\text { voluntario, que sean } \\
\text { usuarios de aceite } \\
\text { de cáñamo y otros } \\
\text { derivados de la } \\
\text { planta de cannabis. }\end{array}$ & NO & \begin{tabular}{|l|} 
Registro de \\
pacientes. Registro \\
de personas \\
naturales o jurídicas \\
importadoras y/0 \\
comercializadoras. \\
Registro de \\
entidades de \\
investigación. \\
Registro de \\
entidades públicas y \\
laboratorios \\
autorizados para la \\
producción.
\end{tabular} & $\begin{array}{l}\text { Registro Nacional } \\
\text { de Usuarios de } \\
\text { Productos Derivados } \\
\text { del Cannabis } \\
\text { (dependiente del } \\
\text { Ministerio de Salud } \\
\text { Pública y Bienestar } \\
\text { Social). }\end{array}$ \\
\hline Otras & & \begin{tabular}{|l|} 
Artículo 3 . Promoción \\
de transferencia tec- \\
nológica necesaria \\
para la producción \\
nacional de canna- \\
bis y sus derivados \\
con fines médicos y \\
científicos (parágrafo \\
$4^{0}$ ). Implementación \\
de iniciativas que \\
desarrollen las \\
comunidades cam- \\
pesinas, los pueblos \\
y comunidades indí- \\
genas con fines \\
médicos y científicos \\
(parágrafo $5^{\circ}$ ). Pro- \\
teger y fortalecer a \\
los pequeños y \\
medianos cultivado- \\
res, productores y \\
comercializadores \\
nacionales de can- \\
nabis medicinal (en \\
el marco de la susti- \\
tución de cultivos ilí- \\
citos) (parágrafo $6^{\circ}$ ). \\
En la reglamentación \\
y expedición de \\
licencias debe prote- \\
gerse la industria e \\
iniciativas nacionales \\
(parágrafo $8^{\circ}$ ). Artí- \\
culo $15^{0}$. Programa \\
Nacional de Preven- \\
ción en la Comuni- \\
dad Educativa.
\end{tabular} & $\begin{array}{l}\text { Artículo 2. Programa. } \\
\text { Créase el Programa } \\
\text { Nacional para el } \\
\text { Estudio y la Investi- } \\
\text { gación del Uso Medi- } \\
\text { cinal de la Planta de } \\
\text { Cannabis, sus deriva- } \\
\text { dos y tratamientos } \\
\text { no convencionales. } \\
\text { Artículo 6. La autori- } \\
\text { dad de aplicación } \\
\text { podrá autorizar el } \\
\text { cultivo de cannabis } \\
\text { por parte del Conicet } \\
\text { e INTA con fines de } \\
\text { investigación médica } \\
\text { y/o cientíica, así } \\
\text { como para elaborar } \\
\text { la sustancia para el } \\
\text { tratamiento que } \\
\text { suministrará el pro- } \\
\text { grama. En todos los } \\
\text { casos, se priorizará y } \\
\text { fomentará la produc- } \\
\text { ción a través de los } \\
\text { laboratorios públicos } \\
\text { nucleados en la } \\
\text { AnLAp; Articulo } 9 \text {. } \\
\text { Créase un Consejo } \\
\text { Consultivo Honorario, } \\
\text { que estará integrado } \\
\text { por instituciones, } \\
\text { asociaciones, organi- } \\
\text { zaciones no guber- } \\
\text { namentales y profe- } \\
\text { sionales del sector } \\
\text { público y privado. }\end{array}$ & $\begin{array}{l}\text { La Secretaría de } \\
\text { Salud reforzará los } \\
\text { programas y accio- } \\
\text { nes con énfasis en la } \\
\text { prevención, trata- } \\
\text { miento, rehabilita- } \\
\text { ción, reinserción } \\
\text { social y control del } \\
\text { consumo de canna- } \\
\text { bis sativa, índica y } \\
\text { americana o mari- } \\
\text { huana y yus deriva- } \\
\text { dos, por parte de } \\
\text { niñas, niños y ado- } \\
\text { lescentes, así como } \\
\text { el tratamiento de las } \\
\text { personas con adic- } \\
\text { ción a dichos narcó- } \\
\text { ticos. El Consejo de } \\
\text { Salubridad General, } \\
\text { a partir de los resul- } \\
\text { tados de la investi- } \\
\text { gación nacional, } \\
\text { deberá conocer el } \\
\text { valor terapéutico o } \\
\text { medicinal que lleve } \\
\text { a la producción de } \\
\text { los fármacos que se } \\
\text { deriven de la canna- } \\
\text { bis sativa, índica y } \\
\text { americana o mari- } \\
\text { huana y sus deriva- } \\
\text { dos, para garantizar } \\
\text { la salud de los } \\
\text { pacientes. }\end{array}$ & $\begin{array}{l}\text { Artículo 296-A. } \\
\text { Comercialización y } \\
\text { cultivo de amapola y } \\
\text { marihuana y su } \\
\text { siembra compulsiva. } \\
\text { Se excluye de los } \\
\text { alcances de lo esta- } \\
\text { blecido en el presen- } \\
\text { te artículo, cuando } \\
\text { se haya otorgado } \\
\text { licencia para la } \\
\text { investigación, impor- } \\
\text { tación y/o comercia- } \\
\text { lización y produc- } \\
\text { ción, del cannabis y } \\
\text { sus derivados con } \\
\text { fines medicinales y } \\
\text { terapéuticos. Artículo } \\
\text { 299. Posesión no } \\
\text { punible. Tampoco } \\
\text { será punible la pose- } \\
\text { sión del cannabis y } \\
\text { sus derivados con } \\
\text { fines medicinales y } \\
\text { terapéuticos, siempre } \\
\text { que la cantidad sea } \\
\text { la necesaria para el } \\
\text { tratamiento del } \\
\text { paciente registrado } \\
\text { en el Ministerio de } \\
\text { Salud. Artículo } 300 \text {. } \\
\text { Suministro indebido } \\
\text { de droga.A excep- } \\
\text { ción del cannabis y } \\
\text { sus derivados, con } \\
\text { fines medicinales o } \\
\text { terapéuticos, que no } \\
\text { es punible, siempre } \\
\text { que se suministre a } \\
\text { pacientes que se } \\
\text { registren en el regis- } \\
\text { tro a cargo del } \\
\text { Ministerio de Salud. }\end{array}$ & \\
\hline
\end{tabular}

Fuente: Elaboración propia. 